Article

\title{
Fudo: An East Asian Notion of Climate and Sustainability
}

\section{Jin Baek}

Department of Architecture and Architectural Engineering, Seoul National University, 1 Gwanak-ro, Gwanak-gu 151-742, Korea; E-Mail: jub34@snu.ac.kr; Tel.: +82-2-880-7079; Fax: +82-2-871-5518.

Received: 15 July 2013; in revised form: 21 August 2013 / Accepted: 2 September 2013 /

Published: 9 September 2013

\begin{abstract}
My paper discusses an East Asian notion of climate and its significance for sustainability. A particular reference is the environmental philosophy of Tetsuro Watsuji (1889-1960), a Japanese philosopher who reflected upon the meaning of climate, or "fudo" in the Sino-Japanese linguistic tradition. Watsuji sees fudo not merely as a collection of natural features - climatic, scenic, and topographical — of a given land, but also as the metaphor of subjectivity, or "who I am". Furthermore, this self-discovery through fudo is never private but collective. By referring to a phenomenological notion of "ek-sistere", or "to be out among other 'I's", Watsuji demonstrates the pervasiveness of a climatic phenomenon and the ensuing inter-personal joining of different individuals to shape a collective sustainable measure in response to the phenomenon. My paper lastly concretizes the significance of fudo and its inter-personal ethical basis for sustainability by dwelling upon cross-ventilation in Japanese vernacular residential architecture. Cross-ventilation emerges only through what Watsuji calls "selfless openness" between different rooms predicated upon the joining of different 'I's soaked in hotness and humidity. Watsuji's fudo thus offers a lesson that without considering the collective humane characteristic of a natural climatic phenomenon, any sustainable act is flawed and inefficient.
\end{abstract}

Keywords: Tetsuro Watsuji; fudo; climate; the inter-personal; sustainability; cross-ventilation; japanese residential architecture

\section{Introduction}

This paper illuminates an East Asian notion of climate and its significance from the perspective of sustainability. A particular reference is the environmental philosophy of Tetsuro Watsuji (1889-1960) 
(Figure 1), a Japanese philosopher who embarked on a journey to Berlin in 1927 in order to study with Martin Heidegger (1889-1976) and who in this process travelled through different climatic zones of the world such as Asia, Middle East, the Mediterrenean, and Western Europe. Due to an unexpected death of his father, Watsuji's study plan was interrupted and he had to return to Japan a year later. However, the experiences Watsuji had en route to Berlin operated as mirrors against which he could reflect the climate of his homeland to discover its characteristics. The experiences also functioned as the basis for his investigation into the significance of the spatiality of the human being. While acknowledging Heidegger's philosophical achievement, Watsuji was simultaneously critical of the Western master by claiming that Heidegger emphasized overly the dimension of time at the expense of disregarding spatiality. Watsuji's ideas about the spatiality of Da-sein came to be crystallized through Fudo (A Climate: A Philosophical Study) published in 1935.

Figure 1. A portrait of Tetsuro Watsuji (Photo by Tanuma, Source: [1].)

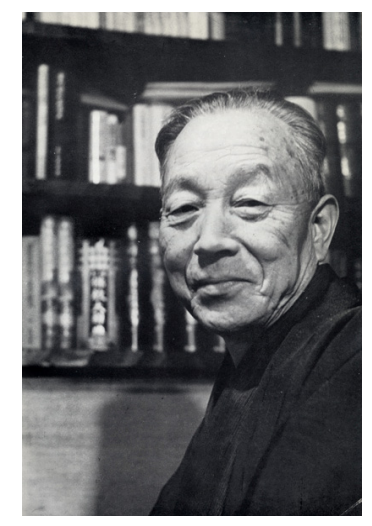

Spatiality meant for Watsuji not the space as pure extension of ever-expanding vacuum, or the scientific sense of the term as an empty background in which things are defined through a three-dimensional coordinate system, but fudo with tangible climatic, scenic and topographical characteristics. Fudo is a term originating from the Sino-Japanese linguistic tradition. It is literally a combination of two Chinese letters: $f u$ means wind, and $d o$, earth. A creative moment in Watsuji's theory of fudo, however, comes with his claim that man and natural phenomena are intertwined in such a way that the phenomena operate as the metaphor for human subjectivity, transcending scientific objectivism. From this concrete intertwined state, or fudo, emerges man and nature as its two abstracted facets. Watsuji further demonstrated the inter-personal dimension of fudo, clarifying that the relationship between man and nature cannot be separated from the relationship between man and man.

With these preliminary observations in mind, the goal of this paper is first to elucidate Watsuji's notion of fudo and in particular his unique view of fudo as the metaphor of human subjectivity. Second, the paper illuminates the inter-personal dimension of fudo by showing both how fudo necessarily operates as a context that embraces different individuals to imbue them with a distinctive climatic quality and how they come to be joined to each other in order to shape a collective measure in coping with the climatic condition. Lastly, the paper concretizes the significance of fudo and its ethical basis for sustainability by dwelling upon cross-ventilation. A particular example is the spatial configuration of machiya, a vernacular Japanese residential architecture of which Watsuji himself offered a profound insight into the occupants' collective patterns of living. 


\section{Fudo as the Metaphor of Human Character}

Watsuji's conception of fudo transcends seeing what surrounds us as a natural environment, in which biological, physical and geographical features exert forces on human living and the human beings in turn transform the environment [1]. For Watsuji, this manner of thinking in which man and nature are treated as two separate entities misses a more fundamental bond between man and climatic phenomena. For him, man and nature are two moments abstracted from this concrete primal bond. Temporality conditions our concrete experience of the world. As an abstraction of this concrete experience, we come up with "time" as a concept. Likewise, "nature" is a concept abstracted from our concrete experience of the world. For Watsuji, before there is nature, there is fudo, or the intertwined state between physical natural phenomena and humanity. One does not see a light as a neutral scientific electromagnetic radiation of a wavelength, but, for instance in the case of a believer in Hinduism, as the undiminished radiance of Shiva. This chiasmic moment between what is physically present and, borrowing a philosophical lingo, subjectivity is the primary mode that governs the relationship between nature and man. It is thus an illusion that there is such a thing as nature independent of and in separation with humanity. Conversely, fudo seeks to overcome this division between man and nature, or this dichotomous framework in favor of the a priori intertwined status between nature and man.

The characteristics of fudo as a chiasmic intertwining are then as follows. First, fudo indicates concrete phenomena in daily life in which, for instance, a physical movement of air is never apprehended as a scientific fact. Rather, the movement appears as a wind in spring that "scatters the cherry blossoms" [1]. What is further significant is the fact that this wind penetrates the human heart. We are found "gladdened or pained in a wind that scatters the cherry blossoms" [1]. What takes place at the outside world is intertwined with the status of the human heart. It is through a series of abstraction that one can reach the horizon of science where neutrality, or indifference to a climatic phenomenon, pervades. In apprehending at what level fudo is operating, we can accordingly establish a tiered system from the concrete, where a climatic quality is intertwined with the human heart, to the abstract, where the climatic quality is treated as a physical quality indifferent to the human heart: from "a spring wind scattering the cherry blossoms to define the human heart gladdened or pained" to "a spring wind scattering the cherry blossoms", then to "a spring wind", then to "a wind", and then finally to a "movement of air" (Chart 1).

Chart 1. Fudo and levels of perception.

A Spring Wind Scattering the Cherry Blossoms to define the human heart gladdened or pained

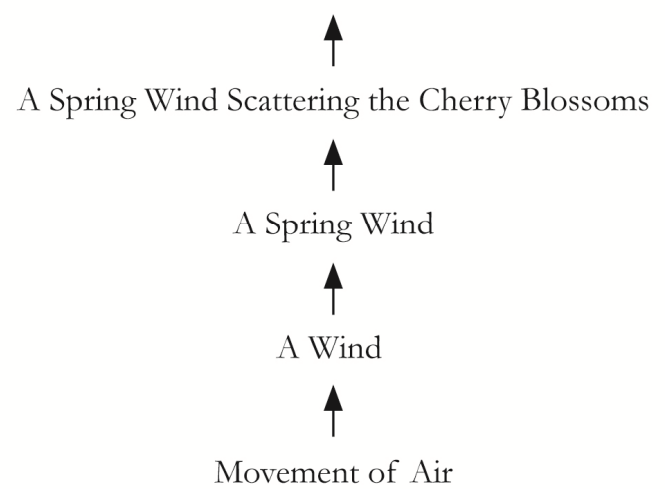


Second, there is a more important point about $f u d o$, and this point makes Watsuji's theory of climate unprecedentedly original. According to Watsuji, fudo is "the agent by which human life is objectified, and it is here that man comprehends himself; there is self-discovery" in it [1]. He expressed the same view with a different phrase elsewhere: "the climatic character is the character of subjective human existence" [1]. What did he mean by this claim that fudo is the agent for the discovery of the human character? His examples included "sabaku". "Sabaku" is the Japanese term for desert - one example being the Arabian Desert around Aden Watsuji himself experienced along the journey to Berlin and another being the Gobi desert that stands between northern China and southern Mongolia. "Sabaku" combines sand $(s a)$ and bleakness (baku) to denote one reality. While "sa" alone indicates sand, in Sino-Japanese linguistic tradition " $s a$ " is necessarily joined with "baku" to signify the desert. For Watsuji, this term points out the fact that "sabaku" is less a substantial stretch of sand than a phenomenon of the human heart-barrenness, loneliness and desolation-formulating an empathetic concord between man and the sandy scenery [1]. Put differently, the barrenness and loneliness of the human heart finds its mirror from the landscape at the outside and is projected empathetically to it. Stating from a different angle, barrenness and loneliness bind the human heart and the landscape into one.

Watsuji then moved to the discussion of the Japanese climate and the Japanese character of which the climate operates as a metaphor. According to him, what distinguishes the climate of Japan from other parts of the world such as Europe is the coupling of "the seasonal and the sudden" [1]. Amidst the cyclic anticipation of the four seasons, the Japanese climate manifests variegated articulations from the winter freeze to the torrential rains of summer and from the foggy dawn to the shower in late afternoon via the atmospheric transparency during the midday. What characterizes the Japanese climate mostly, however, consists in the fact that the summer is both hot and humid [1]. The level of humidity from June to September is over $75 \%$ and the temperature during this period is continuously over 25 degrees in celsius, reaching occasionally even 38 degrees. The amount of rain during this hot season is three to four times the amount of Western European regions, and six to seven times the amount of the Mediterranean. The sunlight and humidity work collaboratively to formulate a series of manifest differences in the mood of the atmosphere. A single day of summer alone arrays "refreshing cool" and "a sudden change on the style of the complete clearing of the weather that follows a sharp summer evening shower in Japan" [1]. Thermal conditions are variegated, too: "the cool of a summer's evening, for example, the freshness of the morning, the violent change, sufficient to bring cold at sunset of an autumn day, the morning cold in winter, enough to shrivel the skin, and, after it, the balmy warmth of an Indian summer day" [1]. This broad range of the Japanese climate is picturesquely represented by the scene of "the bamboo, a native of the tropics, covered in snow" [1] coupling a woody plant of a tropical zone with ice crystals of a freezing region (Figure 2).

What is significant is to note the fact that these features of the climate in Japan mirror the character of the Japanese. In other words, they are not merely environmental facts; such features are borrowing Watsuji's words, "transferred to the description of men's minds and hearts" [1]. The cyclical nature of the climate corresponds to the Japanese character that persists in winter chills in expectation of the mild atmosphere of spring and the sultry heat of summer. This Japanese climate that joins cyclically contrasted and opposing qualities further corresponds to the Japanese character with "a copious outflow of emotion, constantly changing, yet conceals perseverance beneath this change" [1]. The varieties of the climatic conditions displayed even during a single day is also the shadow of the 
Japanese sensitivity to "minute and delicate switches of mood" [1] combined with meditative calmness. Most characteristically, the scene typical of East Asia that joins a tropical woody plant and a crystal of the frigid Siberia is not merely a physical landscape but also a metaphor of humanity, as it mirrors a dialectical, contradictory fusion between silent coldness on surface and burning passion inside, a virtue in human character in East Asia. This dualistic aspect of climate in Japan portrays the ethos of the Japanese as "neither the constant fullness of feeling of the tropics nor the single-toned tenacity of emotion of the cold zone" [1].

Figure 2. Bamboo covered in snow (Jane Butler/Flickrs/Gettyimages).

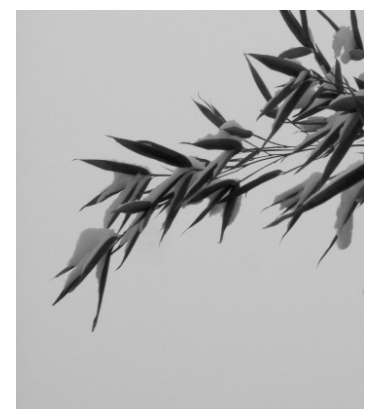

\section{Ethics of the Inter-Personal}

A climatic phenomenon is pervasive, embracing different individuals within the same atmosphere. Put differently, fudo is not something that can be objectified as an entity standing in front of a perceiver. Rather, it formulates a context in which different individuals are located and embraced. While this collective and embracive nature of a climatic phenomenon is quite evident in our daily life-otherwise, we would not be able to greet in the morning without asking consent to others that "it is very hot today" - it is a different matter to theorize why it is the case. In order to demonstrate this fundamentally collective dimension of fudo, I would like to reflect upon the concrete climatic phenomenon cited earlier: "A Spring Wind Scattering the Cherry Blossoms to define the human heart gladdened or pained." It is important to understand here that the discovery of the self as gladdened or pained emerged through the self being intermeshed with the wind. In other words, the self is not the heroic and indifferent subject who centers on an ego to measure the world at the outside, but the self as the capacity to be imbued by the efficacy of the climatic phenomenon, reminding one of the East Asian tradition of defining the self as emptiness. It is not that the "I" feels the atmosphere, but rather the "I" is permeated by the atmosphere. The atmosphere is pre-present before the formation of the "I". The "I" emerges as the result of the interaction with the atmosphere. The pre-presence of the atmosphere further means that the presence is prior to not only the "I", but also the others. The atmosphere penetrates not only the "I", but also the others, too, and both the "I" and the others are equally infected.

In this context of theorizing the fundamentally collective dimension of fudo, Watsuji referred to phenomenology. A particular notion discussed was "ex-sistere" which he defined as "to be out among other "I's" [1]. While discussing what "ex-sistere" itself is would go beyond the scope of this paper, I would like to bring to one's attention here that Watsuji defined it not as "to be out among other individuals", but "to be out among other "I's". In other words, fudo is not simply a context that embraces the "I" and others. Rather, in fudo, there are no others, as the others are transformed into the 
"I"s. It is these "I"s that form a collective bond to cope with a climatic phenomenon in turn. When a severe coldness strikes, the members of a family sit together around a hibatchi, a portable container with burning charcoals inside. The circular formation of the sitting together is none other than the geometric expression of the joining of different "I"s to share and protect the little amount of heat transmitted from the hibatchi and to feel the warmth of the bodies of the other members by sitting tight as if the bodily warmth were complementing the meagerness of the available heat the hibatchi offers. Of course, this bond between different "I"s is applicable to other social situations beyond the confine of the family. When a torrential rain hits a village on a summer day, villagers form a collective bond voluntarily and immediately to fight with the rain, and only collectively may they win. Young males toil in making sand bags, carrying them and stacking them to block the flood. The old and ladies keep themselves busy in preparing emergency food. The children hide themselves in a safe place. In this way, fudo never hits an individual, but a group of people to bind them into different "I"s. Watsuji's theory of climate thus establishes a platform for environmental ethics concerned with the bond between climate and collective environmental measures. It is the context through which self-enclosed individualism is overcome in favor of a unity that cultivates collective environmental measures.

Fudo, as the spatiality of the human being, is necessarily the space where the presence of the others in the form of different "I"s is acknowledged. Indeed, Watsuji went so far as to claim that there is never a man, but men from the beginning. While anthroppos, homme and homo all indicate individuals, man must be understood both in the individual dimension and in the dimension of society, or "the combination or the association of man" [1]. Watsuji's theory of fudo as a milieu that binds the I and others into one operated as the basis for his subsequent study into ethics. In Rinrigaku (Ethics), published two years after Fudo (A Climate: A Philosophical Study), Watsuji's target of critique was individualism which he saw as replacing the notion of the whole mankind with the notion of the individual [2]. In this context, Watsuji analyzed philologically the term ningen that signifies man in the Sino-Japanese linguistic usage. Though being a single word, ningen comprises two Chinese letters: $\operatorname{nin}$ meaning "man" and gen meaning "in-between". Accordingly, the linguistic convention of Ningen is indicative of the East Asian conception of man as fundamentally embedded with the dimension of the collective. By relying partially upon this linguistic proof, Watsuji made even a radical assertion that "every trace of the notion of independent existence must be voided" [2].

To be sure, Watsuji's emphasis on the collective, or "we" should not be considered a form of totalitarianism at the expense of nullifying individual differences. A key to understanding Watsuji's sense of the collective is a dialectical structure in which opposite parties are contrastively joined and dependent on each other for their identification: the father and the mother, the parent and the child, the brother and the sister, and so forth. It is the father that makes a lady to be a mother. It is a parent that makes a boy to be a child. It is a brother that makes a girl to be a sister. This acknowledgement of the opposite is a form of reciprocity, mutual-dependence and co-origination. Watsuji in this context rejected self-sufficiency of a person. One's identity is not within her own self, but in her relationship with the opposite. The identity of a person is not fixed from the beginning, but emerges through a dialectical relationship with the opposite. Consequently, what governs the relationship between one and the opposite is the logic of inverse correspondence, an advanced level of concurrence predicated upon the symmetrical array of asymmetrical qualities. Borrowing words of David A. Dilworth, this balanced, yet inverted, concordance is the principle of "is and yet is not" and that of "simultaneity, and 
bi-conditionality, of opposites without their higher synthesis" [3]. This principle differs from the Hegelian dialectics in that it does not presuppose the formation of a middle ground between thesis and anti-thesis. Citing an example, Watsuji's dialectical position is not destined to collect white and black to formulate gray. For him, what has been formulated through this dialectical process is merely fixed as another static entity, in the process of which the dynamic creative energy stemming from the two parties' contrasted, yet undividable, juxtaposition is gone.

\section{Cross-Ventilation and Ethics of the Inter-Personal}

The ethics of the inter-personal as embedded in Watsuji's notion of climate is significant in sustainability, as it offers an opportunity for us to ground a collective basis for sustainability. One example I can cite in order to exemplify Watsuji's ethics of the inter-personal as the foundation for a sustainable performance is cross-ventilation in Japanese vernacular architecture. As Watsuji pointed out, a major characteristic of the Japanese climate is the combination between the hotness and humidity in summer. In order to understand the implication of this sultry combination for daily life, one needs to be reminded of, first, the wide spectrum of the Japanese climate from summer to winter and, second, how the Japanese cope with the winter. Regarding the second aspect, I would like to comment on the fact that the Japanese did not develop any advanced heating device such as, for instance, the floor heating system called ondol of Korea, her immediately neighboring country. Indeed, spending a night in winter in a Japanese house is tough. The tatami mats are found very cold on skin. The doors and partitions between wooden columns are flimsy, performing poorly in terms of insulation. A limited number of portable, local heating devices such as hibachi, complement this poor thermal performance. Family members literally fight with coldness by being snuggled together around a hibachi, while covering them with a common blanket. Probably, it is in this context of coping with coldness, while only portable localized heating devices are available, that the Japanese culture developed a bathing habit in a hot cypress tub before going to bed.

This insufficient development of heating devices is, however, less a negligence of winter than a focus on summer. In other words, little development of heating devices diametrically means that the Japanese house was developed rather with the aim of managing summer, or more precisely speaking its hot and humid climate. For the Japanese, what was crucial and urgent was to survive in summer by removing humidity combined with hotness effectively, while in winter, as long as they did not freeze to death, they lived passively with coldness. In this context emerges the fluid spatial configuration of the Japanese house (Figures 3 and 4). A wind admitted from the street at the outside travels through different rooms in the process of which it removes humidity and heat. By the time the wind reaches a small central courtyard, its temperature has arisen and comes to be lifted up naturally through the courtyard into the atmosphere (Figure 5).

What is significant is to figure out the social norm that allowed the formation of this flexible spatial configuration and the ensuing cross-ventilation. It was Watsuji who framed again the significance of the flexibility from the perspective of the inter-personal relationship. Watsuji wrote:

None of the rooms are set off from each other by lock and key with a will to separation; in other words, there is no distinction between individual rooms. Even if there is a partitioning by shoji (sliding doors) or fusuma (screens), this is a division within a unity of mutual trust, and is not a 
sign of a desire for separation. So the close and undiscriminating unity of the house does permit such partitioning by shoji or fusuma; but the very fact of the need for partition within this undiscriminating unity is an indication of the passion it contains. So such partitions indicate the existence of antagonism within the house; yet their removal is in itself a show of a completely unbarriered and selfless openness [1].

Figure 3. Open spatiality of Japanese house (Photo: Author).

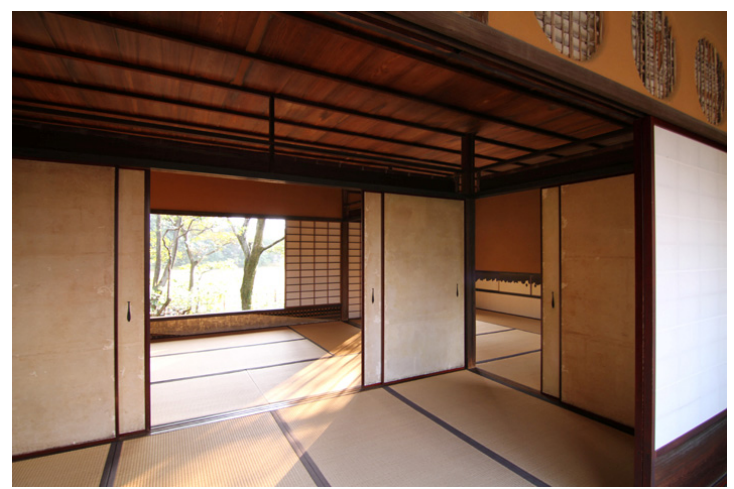

Figure 4. Plan of a machiya (Drawn by Hamed Aali).

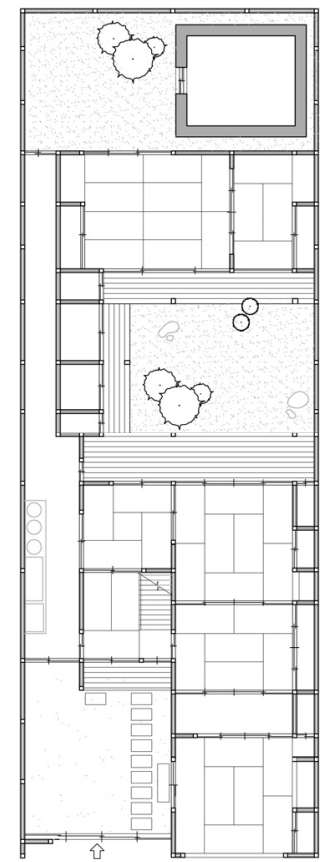

Figure 5. Analysis of cross-ventilation in machiya (Drawn by Hamed Aali and Jiwhan Choi).

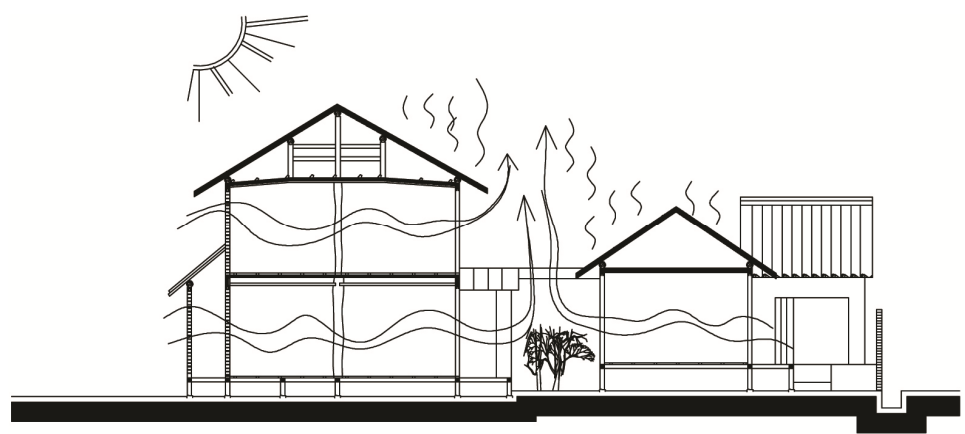


Watsuji characterized effectively the Japanese vernacular house such as machiya in Kyoto, the city where Watsuji resided, as composed of smaller rooms abutting each other without any fixed separations between them. Corridors that separate one room from another are rarely found in the Japanese vernacular house. One can cross over from one room to another directly, formulating what Watsuji defined in the quote above as "a completely unbarriered and selfless openness". It is this "selfless openness" that allows for the cross-ventilation to come into being.

Watsuj's philosophy leads us to illuminate the fundamental bond between "who we are" and climate. This architectural openness is the mirror of the social openness in the relationship between the members of the family. "Selfless openness" is possible only when there arises the joining of different "I"s as standing in "ex-sistere" in the midst of a pervasive and encompassing climatic phenomenon. Tuning different chords gives rise to a harmonious melody; likewise, tuning the relationship among the rooms gives rise to a crossing wind beneficial to all the members of the family. In a sense, there is then no wind unless there is a collective tuning first. In this regard, Watsuji's discussion of climate with the spatial arrangement of the vernacular Japanese house is a paradigmatic image of the social dimension of sustainability: Sustainability is concerned with not merely the relationship of man to available resources, but also the relationship between man and man. Consequently, the inter-personal dimension of "we" grounds sustainability.

\section{Conclusions}

Watsuji's theory of fudo, or climate, is the milieu in which nature and man are intertwined with each other. In this milieu, a seemingly natural climatic phenomenon operates as the metaphor of humanity. In addition, this self-discovery through fudo is never private but collective. That is the reason why Watsuji stated fudo as the mirror of not just "who I am" but also "who we are". Watsuji further discussed a phenomenological idea of "ek-sistere" in order to verify the pervasiveness of a climatic phenomenon beyond the confine of the self-enclosed "I". Fudo is a milieu in which we are found and from which the "I" and others as "different "I's" emerge in reciprocity. In this fashion, Watsuji's fudo reveals an inseparable link between natural phenomena and the dimension of "we" or the ethics of the inter-personal.

Accordingly, Watsuji's fudo opens a path for an extended notion of sustainability that regards not only the relationship between man and nature, but also the relationship between man and man, or the inter-personal mediated through climatic phenomena. As I have demonstrated, cross-ventilation exemplifies effectively the collective basis for a sustainable operation. Without the "selfless openness" predicated upon the joining of different 'I's soaked equally in hotness and humidity, as exemplified in the Japanese vernacular house, there would not be any admitted natural wind that travels through to eliminate heat and humidity efficiently. Watsuji's point on open spatiality and the ensuing cross-ventilation has an immediate lesson for architecture. It leads us to reflect upon critically the mechanical application of privacy by severing one room from another through the implementation of fixed walls and corridors only to nullify any possibility of collectively tuning the rooms and their dividers. In order words, Watsuji's theory leads us to reformulate and re-conceptualize the relationship between one room and another and the role of the corridors in maximizing the benefits of such a passive sustainable method as cross-ventilation. 
Beyond this immediate architectural lesson, I believe Watsuji's theory of fudo is further important for the discourse of sustainability at a theoretical level. At a moment when our interest in the environment is focused on the discovery of new energy sources, Watsuji's profound investigation into the role of fudo as the metaphor of human subjectivity and as the agency of the inter-personal is highly refreshing. This intimacy between nature and man and the correlate inter-personal dimension of fudo are crucial for the contemporary discourse of sustainability. This is because they lead us to go beyond the seemingly narrow concern of sustainability in which men routinely supposed as singular individuals seek to save natural resources upon the moral imperative of "an individual seeking to be a good person". Watsuji's fudo clarifies that without considering the ethical collective humane characteristic of a natural climatic phenomenon, any sustainable act is flawed and inefficient.

\section{Conflicts of Interest}

The authors declare no conflict of interest.

\section{References}

1. Watsuji, T. A Climate: A Philosophical Study; Ministry of Education Printing Bureau: Tokyo, Japan, 1961; pp. 4, 5, 8, 14, 16, 39-40, 135, 137-138, 145, 198, 200-202.

2. Watsuji, T. Watsuji Tetsuro's Rinrigaku: Ethics in Japan; State University of New York Press: Albany, NY, USA, 1996; pp. 9 and 107.

3. Dilworth, D.A.; Nishida, K. Last Writings: Nothingness and the Religious Worldview; Honolulu University Press: Honolulu, HI, USA, 1987; pp. 5-6 and 130-131.

(C) 2013 by the author; licensee MDPI, Basel, Switzerland. This article is an open access article distributed under the terms and conditions of the Creative Commons Attribution license (http://creativecommons.org/licenses/by/3.0/). 